\title{
Analysis of Dynamic Protection Strategy of Southern Hubei Traditional Settlement
}

\author{
Dong $\mathrm{Li}$ \\ Wuhan University of Science and Technology, Wuhan, Hubei 430065, China \\ super_dongli@sina.com
}

\begin{abstract}
Keywords: Southern Hubei; Traditional Settlement; Dynamic Protection; Strategy Research
\end{abstract}
\begin{abstract}
Dynamics" in theory of dynamic protection mainly reflects in protection contents, protection process and protection methods three aspects. Protection situation of traditional settlement in southern Hubei is not as optimistic. Compact community and folk yard developed on geographical environment is on the edge of disappearing. Another extreme opposite is that although some traditional settlements still exist, driven by commerce or interests, they have been whitewashed to be totally different on the basis of "modern aesthetic value". Therefore, as a matter of fact, they lead to the opposite side of settlement protection. In spite of shell of tradition, their intrinsic cultural continuation has been stopped. From the angle of each matter related to dynamic protection, this essay aims at various elements of settlement and adopts different protection methods that fit their development to present diversity of protection process and protection methods so as to seek for direction of sustainable development of traditional settlements in southern Hubei.
\end{abstract}

Introduction

Distinct from static protection of museum style, dynamic protection is a developmental protection method that always place object of protection into dynamic change for the purse of not restricting protection to simple repair as the old settlement, but pointing out future development direction while maintaining. In the meantime, it gives enough thought to native residents' subjective initiative and is cooperative to activate local economy, reaching harmonious coexistence and dynamic balance of "residents-settlement-environment-society".

\section{Protection and Management of Settlement Environment}

No matter in form, space or construction concept, traditional settlement is strong to adapt to environment and makes up together with local geographic position and climatic environment an inseparable integration. In dynamic protection of settlement, environmental protection is the foundation that leads to the sustainable development of settlements.

Mountain Environment of Southern Hubei. Situated in the southern bank of the middle reaches of Yangtze River and to the north of Mufu Mountain, Southern Hubei area is a zone of transition of Mufu Mountain and Jianghan Plain. Its terrain is lowering from southern Mufu Mountain to northern bank of Yangtze River, changing from middle mountain to low mountain, low mountain to hill, hill to plain and appearing an overall trend of mountains running to Mufu and rivers flowing into Yangtze River. In ancient society when science and technology and social productivity are extremely limited, settlements mostly expand in clans or families. In area with complex topography, it is difficult to operate large-scale excavation and backfilling, so residents can only accommodate themselves to environment, mountains and rivers to select construction site by drawing on advantages and avoiding disadvantages as well as adjustment of measures to local conditions ( Fig. 1).

Mountains belong to non-renewable natural resources and an important carrier of farming culture of southern Hubei. Once they are destroyed, there will be tremendous impact on the entire ecology and environment of settlements. However, in high-speed urbanization process, phenomenon of mountain mining and losses have been very common occurrence. To protect overall environment of settlements is not simply a look at settlement itself, but to center on settlement to plan mountain protection zone within 
an area and maintain original mountain pattern and landform to the greatest extent. At the same time, numerous buffer zones can be planned inside protection area for development and adjustment within a reasonable range, which, on one hand, offsets shortages of function of traditional settlement, on the other hand, satisfies habitants' living demands.

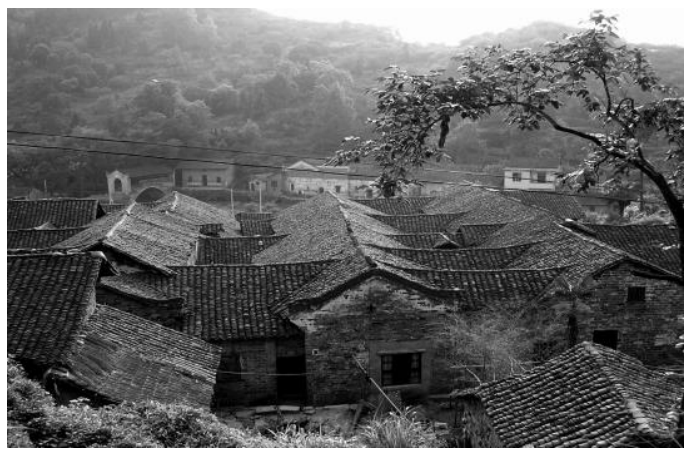

Figure 1. Settlement surrounded by mountains

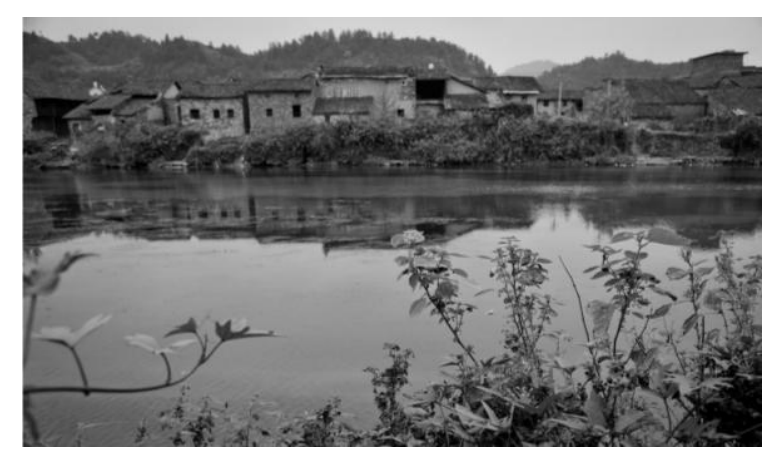

Figure 2. Settlement groups built by rivers

Water Environment of Southern Hubei. Relief in southern Hubei area is complicated with most mountain land and hills and numerous rivers and lakes. In addition to passing Changjiang River, there are more than two hundred rivers of different sizes whose main streams are Lushui River, Ganshui River and Fushui River, and nineteen lakes whose areas are over $500 \mathrm{mu}$. Well-developed water network breeds not only man living in the land, but profound local culture. Abundant water resource provides favorable natural conditions for farmland irrigation, and also brings convenience for people's live and commercial intercourse. Therefore, houses in the area are most built by rivers, gradually leading to settlement or trading market( Fig. 2).

To protect water environment of settlements in southern Hubei, water conservation is the root, for example, to protect sources of water of rivers and springs around settlements, on one hand, it is required to strictly control over industrial wastewater discharged near water source, on the other hand, government should take measures to treat domestic garbage and waste and strengthen pollution monitoring to better water quality.

In the meantime, on the basis of remaining water state unchanged, it is also a way to carry out partial renovation by arrangement of node spaces like footway, green belt, pavilion, gallery bridge and etc. to make settlement more interesting and increase landscape value.

\section{Protection and Restoration of Civil Buildings}

In order to preserve the old appearance of residential architectures in traditional settlements to the best, it is recommended to keep replacement and renewal of building components the least and repair and patch the old components as possible. Only when it's possible to restore can the same materials be used to replace. During repairing, try best to use traditional handicrafts and techniques. If necessary, make a proper use of new technologies as support.

Continue to Use Original Building Components. Basic composition of residential building components contains four parts, namely, roof, wall, ground and indoor component. Internal components can be divided into structural element, doors and windows, bricks, etc. In restoration, in line with the rule of "least intervention", useful building components of civil architectures should be kept as parts of the building.

Continue to Use Components Restored. From Chinese traditional protection and restoration technology and techniques, lots of useful maintenance means, such as grafting, mending, consolidation and other methods are used to better preserve the original. For traditional civil buildings, except components that have to be replaced owing to structural demands, it's better to retain original material repaired. 
In roofing, breakage and deficiency on ridge and tiling can be repaired with original materials and techniques according to preserved style and craft.

In walling, most cases are to repair crack and wall by grouting and plastering respectively. Grouting restoration of cracks includes rinsing, blowing, sealing, grouting, etc. which are used to mend and fill up cracks step by step. Meanwhile, walls dropping or falling off should be repaired by plastering. At last, it is necessary to operate aging treatment on the surface of cracks grouted to make the look the same as the old wall.

In building structure, cracks on wooden beam column, decay and deflection are key parts for repairing. Treatment of cracks can use putty to fill up the cracks to repair narrow cracks, and then paint over with wood oil. For cracks wider than $5 \mathrm{~mm}$, the same quality batten can be used to inlay into the cracks, and then use adhesive to bind together. For cracks between $30 \mathrm{~mm}-50 \mathrm{~mm}$ or even wider, in addition to inlay with battens, iron hoops or glass steel hoops can be used for reinforcement. About rottenness, according to depth of decay, proper corrosion prevention methods can be adopted to solve the problem. If rotten depth is less than half of cross section, it is recommended to remove decayed part and conduct anti-corrosion and mending. If rotten depth is more than half of cross section, according to height of rotten part and position, operate grafting or replacement. To solve bending and deformation, distortion within allowable range can be taken as normal phenomena, that is, 1/250-1/100 of total length of beam and column is permitted range, and it is unnecessary to repair. Component beyond the range but without serious split and decay can be recovered by reverse pressing after being removed. If repeat pressing fails to repair distortion back to permitted range, prior to remain original components, use light-weight assistance as support.

In doors and windows components, apart from reforming distortion, binding cracks and other regular treatment measures, nails can be used to polish partial cracks and corrosion on jamb and center of window. For serious mutilation and decay, it is suggested to use the same materials to replicate according to the original one, and then splice and install.

As for bricks and stones components, if brick and stone carving damaged can be still used after restoration, try best to repair with the same materials and the same techniques right on the part. For brick and stone sculpture with partial damage, they can be repaired by use of mineral materials of close color.

\section{Protection and Reconstruction of Commercial Buildings.}
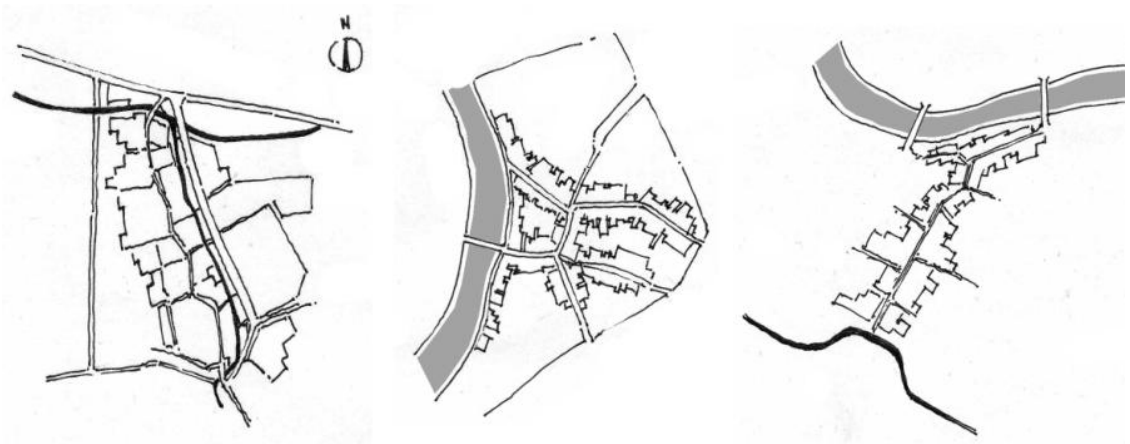

Figure3. Emerging business settlements by rivers, plans of Chibi, Xindian, Baini Ancient Street in sequence

For historical architectures, either regular maintenance, or emergency consolidation, or purposed structural strengthening, or thorough recovery, or even unplanned construction, China has never follow any set forms, making historical information of all periods integrated as a whole. What matters is to preserve an environment, an atmosphere and a style, thus lasting forever expressive meaning of historical architectures. In dynamic protection, even though there are diversified methods available to protect traditional settlements, it is essential to adopt the best one to protection these settlements in accordance with their features and conditions. In traditional settlements of southern Hubei, thanks to 
convenience of waterway transportation and prosperity of tea making and other handicraft businesses, industrial settlement produced with commercial characteristics is the most typical type ( Fig. 3).Such commercial buildings can be protected and reconstructed by reuse and museum-style methods.

Reuse Protection. With change of natural environment and shift of social functions, existing traditional commercial settlements in southern Hubei have been gradually losing its root of survival. Therefore, compared with traditional residential buildings, traditional commercial settlements are much faster being destroyed and disappearing. As modern technology progresses and residents' living standards improve, these commercial buildings located in settlements have lost their primary functions, thus only falling into disuse and waste. To protect these buildings for reuse from the perspective of dynamic protection is, on one hand, to continue historical appearance and culture of commercial buildings so as to inherit the historical information, on the other hand, to meet demands of modernized production and living to synchronize protection and update of commercial buildings and realize better inheritance during development. Reuse protection not only save resources and funds, but inject into traditional settlement fresh blood and new cultural connotation, which enables people to enjoy convenience and satisfaction from modern civilization while experiencing historical culture.

Museum-Style Protection. In traditional settlements, due to influences caused by various social forces and natural forces, part commercial buildings are under bad conditions and have lost their basic functions. What's worse, in spite of restoration, they are unlikely to be put into utilization again, but they are still with cultural, historical and sentimental value. Considering such phenomenon, it is suggested to adopt museum-style protection method according to practical situation. People can select representative cases of commercial buildings, use intentional restoration method, namely, to abstract symbolic element, cultural connotation and purpose of the old buildings to give introduction and display by use of new materials and new processing.

\section{Summary}

Natural environment is a great restrictive condition for development and expansion of traditional settlement. Building and construction of settlement is not to change environment, but to adapt to environment. On one hand, design method of adjustment of measures to local conditions and making the best use of the circumstances is employed to handle connections between settlement and landform. On the other hand, use local natural building materials for construction, which is able to realize uttermost living comfort at a lowest cost of energy consumption. Dynamic protection takes traditional settlement as an organic component of town development and change, and with a view to development and relations, it will bring traditional settlement into category of synchronous progress of city and system to implement protection and development according to local conditions for the purse of recovering traditional settlement.

As Venice Charter stated, "provided that traditional technology fails to solve problems, it is necessary to make use of any modern structures and protection technology to consolidate historic buildings, but such technology should exist on sufficient scientific basis that proves effective by experiment." In restoration work of traditional settlement in southern Hubei, it is preferred to adopt traditional techniques and technology. If necessary, modern technological means can be used to realize best restoration effect. Meanwhile, in addition to protection of settlement form, space and other physical forms, objects of dynamic protection should focus on historical culture, ethnic culture, ecology and other non-physical levels as well as municipal administration, economic civilization, urban planning and other fields.

\section{Acknowledgements}

This Project Supported by the National Social Science Foundation of China(Grant No. 15CG156).

\section{References}


[1] Guan Rui-ming: "Residential class design patterns - The continuation of traditional Chinese residential culture and innovation"'J].Architectural Journal, Vol. 10(2000), No.11, p.40-41(in Chinese)

[2] Guan Rui-ming, Nie Lan-sheng: 'Looking to the Future of the Analogical Design for Traditional

[3] Ruan Yi-san, Li Hong-yan: " Architectural Heritage Conservation in China from View of Authenticity” [J]. Huazhong Architecture, Vol. 26(2008), No.4, p.144-148 (in Chinese)

[4] YuXue-cai:“Activation of Monuments \& Sites Via Tourism: Way of Achieving the Better Effect in Both Conservation and Utilization" [J]. Architecture and Culture, Vol. 15(2010), No.5, p.16-20 (in Chinese)

[5] Zou De-nong, Liu Chong-hong, Zhao Jian-bo:“ China's regional architecture achievements, limitations, and foresight”[J]. Architectural Journal, Vol. 10(2002), No.5, p.4-7 (in Chinese)

[6] Zhao Qun, Liu Jia-ping: "Sustenance and Development of Architectural Culture with Regional Characteristics - Brief Illustration on Sustainable Development of Traditional Vernacular Dwellings"[J]. New Architecture, Vol. 26(2003), No.2, p.24-25 (in Chinese)

[7] Shan Chao-qun, Liu Song-fu: "The Isomorphism of Historical Buildings and the Historical Location” [A]. Architectural History and Theory, Vol. 9(2008), No.2, p.24-25 (in Chinese)

[8] Li Xiaofeng, TanGangyi. Serial Books of Chinese Dwellings: Residents of Hunan and Hubei[M]. Beijing: China's Architectural Industry Press .(2009). (In Chinese)

[9] Zhang Song. An Introduction to Integrated Conservation-A Way for the Protection of Cultural Heritage and Historic Environment [M]. Shanghai:Tongji University Press, (2008). (In Chinese)

[10] Ronald G.Knapp.Asia's Diversity \& Asia's Dwellings:A Geographer's Perspective [C].Traditional

[11] Wang Di, Zhang Tianyu. A Look at Chinese Residential Archetype from a Psychological Point of View[C].Traditional Architecture in Modern Asia(TAMA), Seoul Korea,2002,P157-166. 